\title{
Prevalence of High-risk HPV in Postmenopausal Women with Benign Cervical Cytology - A Population-based Cohort Study
}

\author{
KATRIN CHRISTINE ASCIUTTO ${ }^{1}$, OLA FORSLUND ${ }^{2}$ and CHRISTER BORGFELDT ${ }^{1}$ \\ ${ }^{1}$ Department of Obstetrics and Gynecology at Skåne University Hospital, Lund, Sweden; \\ ${ }^{2}$ Department of Medical Microbiology, Division of Laboratory Medicine at Skåne University Hospital, Lund, Sweden
}

\begin{abstract}
Aim: To compare the clinical performance of human papillomavirus (HPV) $m R N A$ and DNA assays in postmenopausal women. Materials and Methods: A total of 5,925 postmenopausal women were tested with cytology and the Luminex HPV DNA assay. High risk-HPV-positive women with benign cytology underwent a complimentary HPV mRNA assay (APTIMA). Both assays and the cytological testing were repeated after 12 months. Results: A total of 334 women were found to be high-risk HPV-positive; 272 out of these women met the inclusion criteria. At follow-up, 25 (9.2\%) out of the 272 included women had cytological abnormalities. HPV mRNA assay at follow-up had a sensitivity of $84 \%$ (95\% confidence interval $=63.9-95.4 \%)$ and a specificity of $60.2 \%$ (95\% confidence interval $=53.7-66.3 \% ; p=0.0003$ ) to detect these lesions. Corresponding values for the HPV DNA assay were $88 \%$ (95\% confidence interval $=68.8-97.4 \%$ ) and $43.5 \%$ (95\% confidence interval $=37.2-49.4 \%)$. Conclusion: The HPV mRNA assay offers a comparable sensitivity but a higher specificity than the HPV DNA assay in detecting precancerous cervical lesions.
\end{abstract}

Organized screening programs for the detection of cervical dysplasia have been shown to reduce the number of cervical cancer cases by improving early detection of precancerous lesions and, at the same time, to enhance the overall survival rate of patients with cervical cancer (1-3).

While the European guidelines state that adequate population coverage for primary screening should be $85 \%$ or more (2), the coverage for cervical cancer screening in Sweden is about $80 \%$. Almost half of cervical cancer cases

Correspondence to: Katrin Christine Asciutto, MD, Ph.D., Department of Obstetrics and Gynecology, Skåne University Hospital, SE-221 85 Lund, Sweden. Tel: + 46 46171000, Fax: + 46 46157868, e-mail: christine.asciutto@yahoo.com

Key Words: High-risk HPV, postmenopausal women, HPV DNA, mRNA testing. are diagnosed in women who are not participating in the screening program (4).

Even though the screening program covers women aged between 23 and 65 years of age, the National Board of Health and Welfare reported in 2006 that more than $60 \%$ of the women diagnosed with cervical cancer in Sweden were older than 50 years (5). In another audit regarding the frequency of cervical cancer in the southern region of Sweden, it was observed that between 1999 and 2001, 26\% of all affected women were older than 65 years, resulting in an incidence number of 22 cases (3). All women of this age group were found to have clinical symptoms at diagnosis and the corresponding cancer stages were more advanced when compared to those cases found during the screening age. In agreement, we recently observed that $25 \%$ (31/126) of invasive cancer cases (SCC and adenocarcinoma) were above 65 years in the period of year 2016 and 2017 in the southern region of Sweden (Skåne) (Personal communication Gunilla Thorn).

To improve the screening coverage for postmenopausal women and identify individuals at risk for the development of cervical pre-cancer, the county of Skåne in Sweden offers women aged 60-65 years the possibility of a final screening control called the exit test, which is a combined liquid-based cytology (LBC) specimen and a complementary high-risk human papillomavirus (HR-HPV) analysis. The sensitivity of a cytological sample alone is known to be lower in postmenopausal women, while the combination of cytology and HPV analysis increases the sensitivity of finding highgrade pre-cancerous lesions (6). A negative HPV result is a better indicator in this age group than a corresponding benign finding on cytology (7).

Furthermore, the pooled evaluation of four randomized trials conducted in Europe estimated that primary HPV screening in postmenopausal women might prevent 32\% more potential cases of cervical cancer than might cytology (8). Therefore HR-HPV testing appears to be an independent, objective method that may be helpful for the further risk stratification of postmenopausal women who are about to be excluded from the regular screening program. 


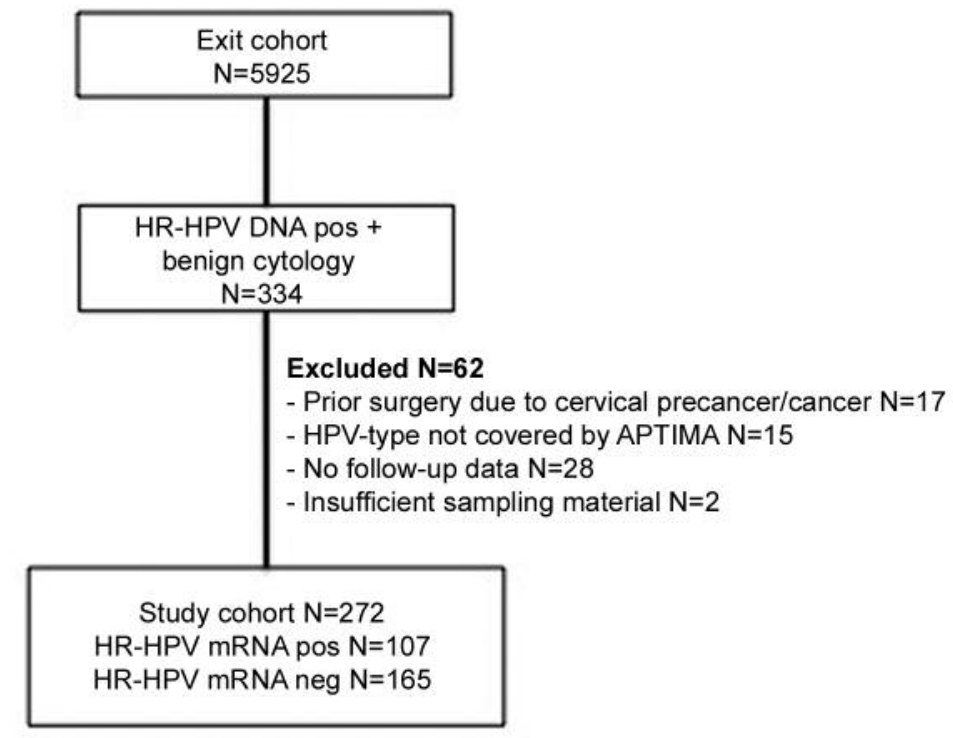

\author{
HPV=Human Papillomavirus \\ $\mathrm{HR}=$ High-risk \\ neg=Negative \\ pos=Positive
}

Figure 1. Flow-chart presenting inclusion criteria and baseline data .
The aim of the present study was to evaluate the prevalence of HR-HPV infections in women 60 to 65 years of age with normal cytology findings at their final screening examination. In addition, we compared the clinical performance of a commercial HPV E6/E7 mRNA assay to that of an in-house modified GP5+/6+ (MGP) polymerase chain reaction (PCR)Luminex HPV DNA method regarding the prediction of cervical dysplasia.

\section{Materials and Methods}

Since January 2013, the recommendation of the organized cervical screening program in the county of Skåne is to perform an additional test in women aged 60-65 years of age before they leave the regular program. This so-called 'exit test' is performed as a combined test including testing for HPV and cytology. Women with normal findings on cytology and HR-HPV infection according to the in-house MGP-PCR Luminex method were eligible for inclusion and received further testing with an mRNA HPV assay (APTIMA; Hologic, San Diego, CA, USA) at baseline and follow-up.

Exclusion criteria included a history of cervical neoplasia or treatment of cervical disease such as the loop electrical excision procedure, hysterectomy or trachelectomy, and ongoing oncological treatment at the time the exit test was performed (Figure 1).

Screening histories encompassing the 10 years prior to the exit test were retrieved from the medical charts.

One year after the exit test, the women were invited for a gynecological check up which involved obtaining an LBC sample and co-testing with both HPV detection assays. All cases with cervical pathology on LBC and a positive HR-HPV test underwent colposcopic assessment.

Pathological LBC results were defined as low-grade squamous intraepithelial lesions (LSILs), atypical squamous cells of undetermined significance (ASCUS), high-grade intraepithelial lesions (HSILs), and atypical glandular cells (AGCs) according to the Bethesda classification (9).

The presence of the same HR-HPV genotype at inclusion and at follow-up was defined as a persistent infection.

The MGP-PCR Luminex HPV DNA assay detects several HPV types simultaneously $(10,11)$. Initially, sample DNA was purified by MagnaPure LC (Roche, Indianapolis, IN, USA) and then HPV DNA was amplified by PCR with MGP primers (11). After amplification, Luminex-based HPV genotyping allows the identification of the following HR-HPV types: 16, 18, 31, 33, 35, $39,45,51,52,56,58,59$, and the probable HR type 68 (A and B), as well as the possibly HR types $26,53,66,67,69,73$ and 82 , as described by the classification of the international Agency for Research on Cancer (IARC) of 2012 (12). In the present study, probable and possible HR-HPV types were classified as HR-HPV types.

The APTIMA HPV E6/E7 mRNA assay (Hologic, Inc.) qualitatively detects E6/E7 mRNA from 14 HR HPV types: 16, 18, $31,33,35,39,45,51,52,56,58,59,66$ and 68 .

The proportion of HPV E6/E7 mRNA positivity was calculated for each of these $14 \mathrm{HR}$ HPV types, as well as for HPV 67 (APTIMA is known to cross-react with HPV 67, Kit insert, APTIMA HPV Assay, nr 503744), as determined by the MGP-PCR Luminex HPV DNA assay. 


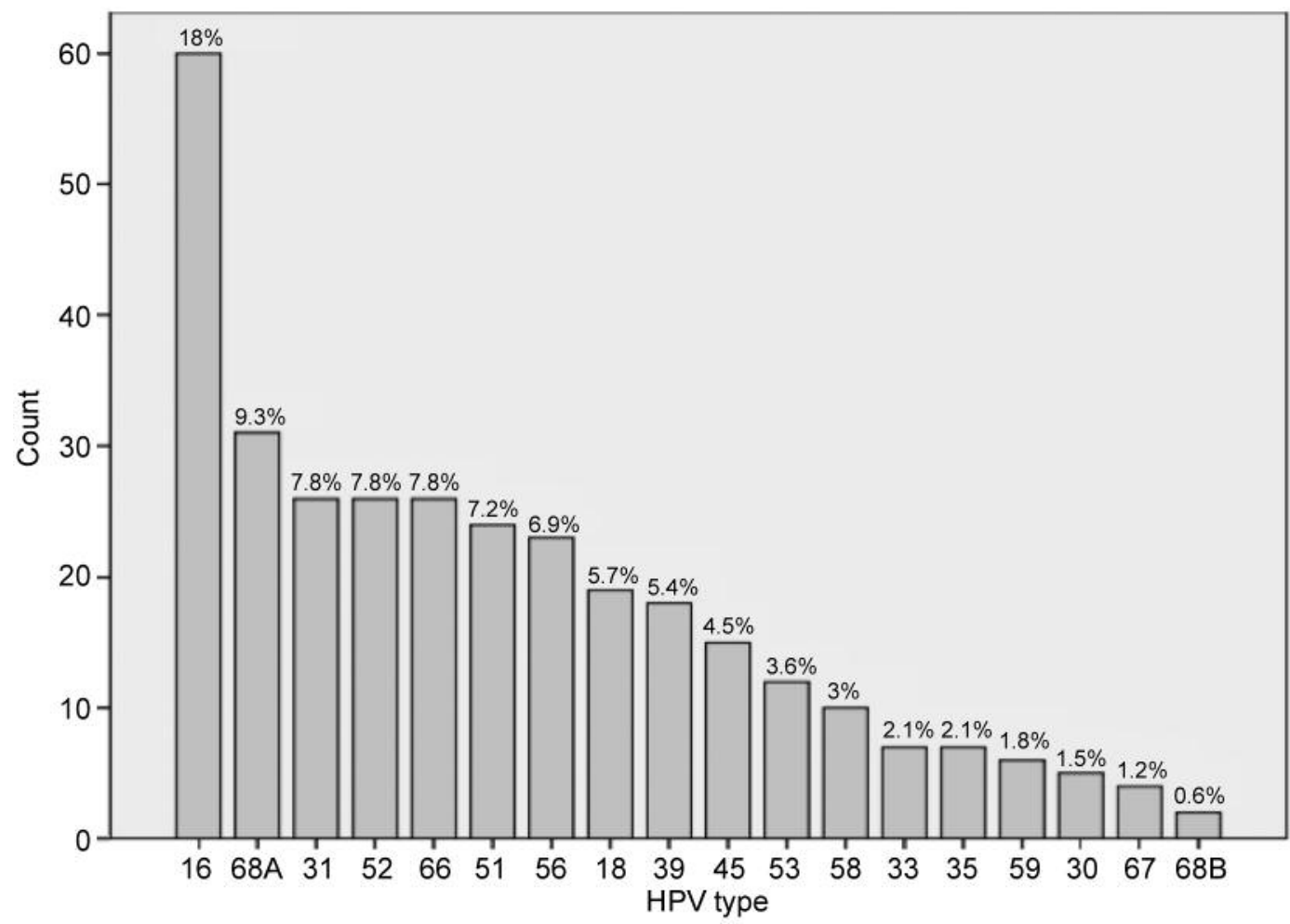

Figure 2. Frequency of high-risk HPV types in 334 out of 5,925 women, 60 to 65 years of age, with normal cytology.

Statistical comparisons were based on two-sided chi-square tests. All comparisons were two-sided, and a 5\% level of significance was applied. The strength of association between the HPV mRNA results at baseline and the presence of cytological alterations and HR-HPV persistence at follow-up was measured using the odds ratio (OR) and the corresponding $95 \%$ confidence interval (CI).

The statistical analyses were performed using SPSS version 19.0 or higher (IBM Corp., Amonk, NY, USA) and Omnistat (SBU, Trelleborg, Sweden)

\section{Results}

In the organized screening, 5,925 women aged 60 to 65 years had normal cytology. HR-HPV DNA infection was found in $5.6 \%(334 / 5925)$ of these women. The distribution of the different HR-HPV types is shown in Figure 2. The mean age $( \pm$ SD) was $61.9 \pm 1.7$ years and all women were postmenopausal. Two or more HR-HPV genotypes were detected in $24 \%$ (79/334) of the women.

Out of the 272 women who were included in the study, 93\% (253/272) had a documented screening history. The majority of women $(98 \%, 249 / 253)$ had benign cytology in their screening records encompassing the 10 years prior to the exit test. In three cases, screening history contained solitary cases of LSIL besides otherwise benign cytological findings. Only one woman had a documented HSIL that was diagnosed about 9 years prior to the exit test. The lesion head been treated conservatively.

At 11-26 months after inclusion, all 272 women with HRHPV DNA infection underwent cytology and both HPV tests. Three women had cytological HSIL, three LSIL and 19 had ASCUS, whereas 247 had normal cytology (Table I). All HSIL and three LSIL cases were histologically confirmed via cervical biopsy. In 16 patients with cytological findings of ASCUS, no tissue sample was obtained due to normal findings on colposcopy, and in the remaining three cases, histology showed benign lesions.

A negative HR-HPV DNA test at follow-up was found in $40.4 \%(110 / 272)$ of the women that were HPV DNApositive at baseline (Table II). Women presenting with HPV mRNA at baseline were more often found to have persistent HPV types or other HPV types at follow-up compared to women without detectable HPV mRNA at baseline $(82.2 \%, 88 / 107$ vs. $46.7 \%, 77 / 165$; OR=5.2, $95 \%$ $\mathrm{CI}=3.0-9.5, p<0.0001)$.

Among women with HPV mRNA or without HPV mRNA at baseline, $16.8 \%(18 / 107)$ and $4.2 \%$ (7/165), respectively, had abnormal cytology at follow-up $(\mathrm{OR}=4.695 \% \mathrm{CI}=1.8$ $11.3, p=0.0011$ ). 
At follow-up, HPV mRNA was detected in 38\% (91/237) of the samples with a single HR-HPV type (Table III). Among women with a persistent HR-HPV DNA type, 50\% $(65 / 130)$ had multiple HR-HPV types at inclusion. At least one persistent HR-HPV type was detected in 58\% (158/272) of all included women.

At baseline, the HPV mRNA assay was positive in $39.3 \%$ (107/272) of HR-HPV DNA-positive women (Table II). All three women with HSIL and $68.1 \%(15 / 22)$ of those with LSIL or ASCUS findings on follow-up cytology were HPV mRNA-positive at baseline. At the follow-up examination, mRNA was found in $44.1 \%(120 / 272)$ of the women (Table II). Five women $(1.8 \%)$ were HPV DNA-negative and mRNA-positive at follow-up (Table III).

The mRNA assay at baseline was positive in 18 out of 25 (72\%; 95\% CI=50.6-87.9\%) women who developed HSIL, LSIL or ASCUS, and the negative predictive value (NPV) was $95.7 \%$ (95\% CI=92.3-97.7\%) (Table II).

The presence of HPV mRNA at follow-up had a sensitivity of $84.0 \%(95 \% \mathrm{CI}=63.9$ to $95.4 \%)$ for the detection of cytological abnormality, with specificity of $60.2 \%(95 \%$ $\mathrm{CI}=53.7$ to $66.3 \% ; p=0.0003)$ and NPV was $97.4 \%(95 \%$ $\mathrm{CI}=93.7$ to $98.9 \%$ ) (Table II). The DNA assay at follow-up had a corresponding sensitivity of $88.0 \%$ (95\% CI 68.8 to 97.4), a specificity of $43.5 \%$ (95\% CI=37.2 to $49.4 \%$ ), and an NPV of $97.3 \%$ (95\% CI=92.4 to $99.05 \%)$. All three patients with cytological findings of HSIL had positive HPV mRNA and HR-HPV DNA results at follow-up.

\section{Discussion}

In the current study the prevalence of HR-HPV in postmenopausal women aged 60 to 65 years with normal cytology in the organized screening program in southern Sweden was $5.6 \%$.

Seven percent $(7.4 \%)$ of these women developed cytological abnormalities after a mean follow-up time of 14 months.

The exit test was performed as co-testing as it is stated in current literature that HR-HPV testing has a higher sensitivity in postmenopausal women compared to conventional screening with Pap smear or LBC. The latter is reported to be effective in only $20 \%$ of women aged 50 years or older (13). HR-HPV testing has been found to be three times more sensitive than cytology in revealing lesions classified as cervical intraepithelial neoplasia grade two or worse (CIN2+) in postmenopausal patients (6). Indeed, due to positive results on both HR-HPV DNA and HPV mRNA testing, we identified three women that developed HSIL during follow-up.

The impaired sensitivity of cytological specimens might be due to quality loss caused by vaginal atrophy or anatomical difficulties in reaching the transformation zone, which is normally retracted in postmenopausal women. Furthermore,
Table I. Human papillomavirus (HPV) types at baseline in relation to cytology at follow-up.

\begin{tabular}{lrclr}
\hline & \multicolumn{3}{c}{ Cytology at follow-up, n } & \\
\cline { 2 - 4 } HPV type & Normal & LSIL/ASCUS & HSIL & Total \\
\hline 16 & 49 & 2 & 1 & 52 \\
18 & 14 & 1 & 1 & 16 \\
30 & 3 & 1 & 0 & 4 \\
31 & 23 & 1 & 0 & 24 \\
33 & 9 & 0 & 1 & 10 \\
35 & 6 & 0 & 0 & 6 \\
39 & 15 & 1 & 0 & 16 \\
45 & 11 & 2 & 0 & 13 \\
51 & 18 & 1 & 0 & 19 \\
52 & 22 & 1 & 0 & 23 \\
56 & 16 & 2 & 0 & 18 \\
58 & 6 & 1 & 0 & 7 \\
59 & 4 & 0 & 0 & 4 \\
66 & 18 & 7 & 0 & 25 \\
67 & 4 & 1 & 0 & 5 \\
68 A & 27 & 1 & 0 & 28 \\
$68 B$ & 2 & 0 & 0 & 2 \\
\hline Total & 247 & 22 & 3 & 272 \\
& $90.2 \%$ & $8.1 \%$ & $1.6 \%$ & \\
\hline
\end{tabular}

ASCUS: Atypical squamous cells of undetermined significance; HSIL: high-grade squamous intraepithelial lesion; LSIL: low-grade squamous intraepithelial lesion.

obtaining an adequate sample in older women can be challenging as gynecological examination is associated with increased discomfort due to the physiological lack of estrogen.

While HPV screening is not recommended in younger women due to the high regression rate $(14,15)$ and the risk of overtreatment, HPV screening is considered a more efficient tool for risk stratification in postmenopausal women due to the lower rate of HR-HPV infection in this age group (16-18). Due to their less intense exposure to HR-HPV after reproductive age, postmenopausal women are purportedly less likely infected to be with a new acquired HR-HPV type (19). Nevertheless, reflex cytological testing on the same sample should be performed before scheduling postmenopausal HRHPV-positive women for further colposcopy.

There is no national or international consensus regarding the age at which cervical screening should be terminated, as an undeniable number of women are still diagnosed with cervical cancer in the last third of their lives (20). The expected lifetime of women in Sweden is 84 years and there are national studies indicating that the mean age of patients diagnosed with invasive cervical cancer is increasing. In particular, a higher percentage of affected women was found in those aged 69 years or older $(21,22)$. Furthermore, the current literature gives evidence that there is a second peak 
Table II. High-risk human papillomavirus (HR-HPV) DNA and mRNA at baseline related to cytology at follow-up.

\begin{tabular}{|c|c|c|c|c|c|c|c|c|}
\hline \multirow[b]{2}{*}{ HR-HPV } & \multicolumn{3}{|c|}{ Cytology at follow-up, $\mathrm{n}$} & \multicolumn{5}{|c|}{ HR-HPV results in relation to LSIL+HSIL in follow-up } \\
\hline & Normal & LSIL/ASCUS & HSIL & Total & $\%$ & Sensitivity & Specificity & Negative predictive value \\
\hline DNA positive at baseline & 272 & 0 & 0 & 272 & $100.0 \%$ & Reference & & \\
\hline DNA positive at follow-up & 140 & 19 & 3 & 162 & $59.6 \%$ & $88.0 \%$ & & \\
\hline DNA negative at follow-up & 107 & 3 & 0 & 110 & $40.4 \%$ & & $43.5 \% *$ & $97.27 \%$ \\
\hline mRNA positive at baseline & 89 & 15 & 3 & 107 & $39.3 \%$ & $72.0 \%$ & & \\
\hline mRNA negative at baseline & 158 & 7 & 0 & 165 & $60.7 \%$ & & $64.7 \%$ & $95.7 \%$ \\
\hline mRNA positive at follow-up & 99 & 18 & 3 & 120 & $44.1 \%$ & $84.0 \%$ & & \\
\hline mRNA negative at follow-up & 148 & 4 & 0 & 152 & $55.9 \%$ & & $60.2 \% *$ & $97.4 \%$ \\
\hline
\end{tabular}

ASCUS: Atypical squamous cells of undetermined significance; HSIL: high-grade squamous intraepithelial lesion; LSIL: low-grade squamous intraepithelial lesion.

for the overall prevalence of oncogenic and non-oncogenic HPV infections in women aged 55 years or older which can be related to more active sexual behavior or reactivation of latent infections due to impaired immune function (23).

The HR-HPV prevalence of $5.6 \%$ found in our patient cohort is comparable to the results of other recent studies reporting frequencies between 5 and $14 \%$ in postmenopausal women $(6,24)$. Even though HR-HPV type 16 was found to be the predominant genotype, we found a relatively high frequency of double or multiple HR- HPV infections at inclusion $(29 \%, 79 / 272)$ and follow-up $(18.3 \%, 50 / 272)$. Furthermore, we found a relatively high frequency of HPV type $68 \mathrm{~A}$ at inclusion and follow-up, and to the best of our knowledge this is the first report showing that this subtype predominates among postmenopausal women.

Our results suggest that the HPV profile found in postmenopausal women differs from those encountered in younger women, comprising HR-HPV types that are not covered by the actual vaccination programs using two- or four-valent HPV vaccines. These observations are consistent with the findings of some publications analyzing the trends of HR-HPV distribution in different age groups $(25,26)$.

Even though HR-HPV infections seem to have a higher and faster clearance rate in older women and are less likely to progress to precancer lesions $(19,27)$, our findings indicate that it might be of clinical value to identify those cases with HR-HPV mRNA infection that may benefit from continued screening.

Concerning prediction for the presence of HSIL or LSIL at follow-up, the MPG-PCR Luminex HPV DNA assay had a similarly high sensitivity to the HPV mRNA assay but the mRNA assay had a higher specificity. Positive mRNA assay at baseline had a similar sensitivity in predicting LSIL or HSIL at follow-up with higher specificity than the DNA assay at follow-up. Both methods were found to have an excellent NPV for HSIL, both at baseline and follow-up. The promising results
Table III. Single human papillomavirus (HPV) type infections in relation to mRNA at follow-up.

\begin{tabular}{lccr}
\hline & \multicolumn{2}{c}{ mRNA } & \\
\cline { 2 - 3 } HPV DNA & Negative & Positive & Total \\
\hline 16 & 6 & 12 & 18 \\
18 & 2 & 2 & 4 \\
30 & 1 & 2 & 3 \\
31 & 7 & 11 & 18 \\
33 & 5 & 2 & 7 \\
35 & 0 & 1 & 1 \\
39 & 3 & 5 & 8 \\
45 & 1 & 3 & 4 \\
51 & 1 & 3 & 4 \\
52 & 2 & 10 & 12 \\
56 & 3 & 4 & 7 \\
58 & 2 & 3 & 1 \\
59 & 0 & 10 & 14 \\
66 & 4 & 3 & 5 \\
67 & 2 & 14 & 16 \\
68 A & 2 & & 107 \\
Negative & 102 & 5 & 237 \\
\hline Total & 146 & 91 & \\
& $61.6 \%$ & $38.4 \%$ & \\
\hline
\end{tabular}

of the HPV mRNA assay may be explained by the fact that it detects mRNA of the onco-proteins E6 and E7, expressed in cases of active, ongoing infection. Therefore, the mRNA-based testing method seems to have the potential to differentiate between postmenopausal women with inactive or transient vitiations and those with ongoing, clinically significant HRHPV infections associated with an elevated risk for the development of pre-cancerous cervical lesions $(28,29)$. 
Another advantage of the HPV mRNA assay is the possibility to use it on vaginal cells collected by self-sampling (30). As a proportion of cervical cancer cases appear in women with missing or incomplete screening history, this practical issue might be of clinical importance (3).

Furthermore, a recently performed Swedish cohort study, based on cytological data, indicate that the incidence of cervical cancer in women up to 80 years of age is significantly higher in those cases who have not been screened or have been inadequately screened after 50 years of age (31). Therefore, the implementation of alternative screening strategies such as the self-sampling procedure might be of clinical interest as it can help to reach those postmenopausal women who are reluctant to undergo a gynecological examination or to attend a medical facility.

Another advantage of the HPV mRNA assay is its potential regarding the triage of patients with ASCUS and LSIL lesions $(32,33)$. Even though ASCUS lesions occur less often in postmenopausal than in premenopausal women (34-36), they were the most common type of cytological alteration found in our patient cohort. As in elderly women the diagnosis of ASCUS and other lowgrade cytological lesions can be caused by a misinterpretation of the effects of epithelial aging, an objective screening method or tool that can differentiate between minor non-HPV-related cellular changes and clinically relevant precursor lesions is needed.

A meta-analysis conducted by Arbyn et al. comparing the accuracy of the APTIMA E6/E7 HPV RNA assay and the Hybrid Capture 2 test which utilizes signal amplification technology for HR-HPV DNA detection, reported a higher specificity of $19 \%(8-29 \%)$ for the triage of ASCUS and of $37 \%(22-54 \%)$ for the triage of LSIL without loss of sensitivity (32) for the APTIMA assay.

According to the findings of literature $(32,37,38)$ and our own data, the HPV mRNA assay has the potential to be used as a screening tool in postmenopausal women as it likely will reduce the number of unnecessary clinical examinations and colposcopies due to its superior specificity compared with HPV-DNA analyses and its very high NPV.

A limitation of the present study is the fact that only HRHPV positive women with accompanying cytological alterations were scheduled for further colposcopic examination. However, this clinical procedure is in line with the current national guidelines for cervical cancer prevention.

More studies with larger cohorts, longer follow-up documentation and additional clinical evaluation of all women testing positive for HR-HPV mRNA or DNA are needed to confirm our assumption that prolonged HR-HPV mRNA screening can lead to a reduction or down-staging of precancerous and cancerous cervical lesions in postmenopausal women.
Based on the presented results, it seems reasonable to perform HPV or co-testing at the age of 60 to 65 years in order to identify those women with an ongoing HR-HPV infection who are at risk of subsequently developing cervical abnormalities. We suggest that patients diagnosed with positive for HR-HPV infection should be offered extended screening with a further HPV test and reflex cytology within 2 or 3 years. In the case of a persistent HR-HPV infection or pathological cytological findings, a colposcopic examination is recommended. Women with a negative co-testing result at the exit test do not need further testing, as earlier studies have shown a very low incidence rate of cervical cancer after a double negative test (39).

\section{Funding}

This work was supported by Grants from Governmental funding (ALF) and Region of Scania. Funding sources had no influence on the study design or the interpretation of results.

\section{Conflicts of Interest}

None of the Authors have declared any conflicts of interest in regard to this study.

The study was approved by the Regional Ethics Board in Lund (Reference number DNR 2013/390).

\section{References}

1 Arbyn M, Rebolj M, De Kok IM, Fender M, Becker N, O’Reilly $M$ and Andrae B: The challenges of organising cervical screening programmes in the 15 old member states of the European Union. Eur J Cancer 45(15): 2671-2678, 2009.

2 Arbyn M, Herbert A, Schenck U, Nieminen P, Jordan J, McGoogan E, Patnick J, Bergeron C, Baldauf JJ, Klinkhamer P, Bulten J and Martin-Hirsch P: European guidelines for quality assurance in cervical cancer screening: Recommendations for collecting samples for conventional and liquid-based cytology. Cytopathology 18(3): 133-139, 2007.

3 Andrae B, Kemetli L, Sparen P, Silfverdal L, Strander B, Ryd W, Dillner J and Tornberg S: Screening-preventable cervical cancer risks: Evidence from a nationwide audit in sweden. J Natl Cancer Inst 100(9): 622-629, 2008.

4 Stenvall H, Wikstrom I, Backlund I and Wilander E: Accuracy of HPV testing of vaginal smear obtained with a novel selfsampling device. Acta Obstet Gynecol Scand 86(1): 16-21, 2007.

5 The National Board of Health and Welfare: Cancer incidence in Sweden 2008. Stockholm: The National Board of Health and Welfare; 2009.

6 Gyllensten U, Lindell M, Gustafsson I and Wilander E: HPV test shows low sensitivity of Pap screen in older women. Lancet Oncol 11(6): 509-510; author reply 510-501, 2010.

7 Cuzick J, Clavel C, Petry KU, Meijer CJ, Hoyer H, Ratnam S, Szarewski A, Birembaut P, Kulasingam S, Sasieni P and Iftner T: Overview of the european and North American studies on HPV testing in primary cervical cancer screening. Int J Cancer 119(5): 1095-1101, 2006. 
8 Ronco G, Dillner J, Elfstrom KM, Tunesi S, Snijders PJ, Arbyn M, Kitchener H, Segnan N, Gilham C, Giorgi-Rossi P, Berkhof J, Peto J, Meijer CJ and International HPVswg: Efficacy of HPV-based screening for prevention of invasive cervical cancer: Follow-up of four European randomised controlled trials. Lancet 383(9916): 524-532, 2014.

9 Solomon D, Davey D, Kurman R, Moriarty A, O'Connor D, Prey M, Raab S, Sherman M, Wilbur D, Wright T Jr., Young N, Forum Group M and Bethesda W: The 2001 Bethesda system: Terminology for reporting results of cervical cytology. JAMA 287(16): 2114-2119, 2002.

10 Schmitt M, Bravo IG, Snijders PJ, Gissmann L, Pawlita M and Waterboer T: Bead-based multiplex genotyping of human papillomaviruses. J Clin Microbiol 44(2): 504-512, 2006.

11 Soderlund-Strand A, Carlson J and Dillner J: Modified general primer pcr system for sensitive detection of multiple types of oncogenic human papillomavirus. J Clin Microbiol 47(3): 541546, 2009.

12 Munoz N, Bosch FX, de Sanjose S, Herrero R, Castellsague X, Shah KV, Snijders PJ, Meijer CJ and International Agency for Research on Cancer Multicenter Cervical Cancer Study G: Epidemiologic classification of human papillomavirus types associated with cervical cancer. N Engl J Med 348(6): 518-527, 2003.

13 Gustafsson L, Sparen P, Gustafsson M, Pettersson B, Wilander E, Bergstrom R and Adami HO: Low efficiency of cytologic screening for cancer in situ of the cervix in older women. Int $\mathrm{J}$ Cancer 63(6): 804-809, 1995.

14 Evander M, Edlund K, Gustafsson A, Jonsson M, Karlsson R, Rylander E and Wadell G: Human papillomavirus infection is transient in young women: A population-based cohort study. J Infect Dis 171(4): 1026-1030, 1995.

15 Ho GY, Studentsov YY, Bierman R and Burk RD: Natural history of human papillomavirus type 16 virus-like particle antibodies in young women. Cancer Epidemiol Biomarkers Prev 13(1): 110-116, 2004.

16 Zhao C, Zhao S, Heider A and Austin RM: Significance of highrisk human papillomavirus DNA detection in women 50 years and older with squamous cell papanicolaou test abnormalities Arch Pathol Lab Med 134(8): 1130-1135, 2010.

17 Sherman ME, Schiffman M, Cox JT and Atypical Squamous Cells of Undetermined Significance/Low-Grade Squamous Intraepithelial Lesion Triage Study G: Effects of age and human papilloma viral load on colposcopy triage: Data from the randomized atypical squamous cells of undetermined significance/low-grade squamous intraepithelial lesion triage study (ALTS). J Natl Cancer Inst 94(2): 102-107, 2002.

18 Bruner KS and Davey DD: Asc-us and hpv testing in women aged 40 years and over. Diagn Cytopathol 31(5): 358-361, 2004

19 Goodman MT, Shvetsov YB, McDuffie K, Wilkens LR, Zhu X, Thompson PJ, Ning L, Killeen J, Kamemoto L and Hernandez BY: Prevalence, acquisition, and clearance of cervical human papillomavirus infection among women with normal cytology: Hawaii human papillomavirus cohort study. Cancer Res 68(21): 8813-8824, 2008.

20 Elit L: Role of cervical screening in older women. Maturitas 79(4): 413-420, 2014.

21 Pettersson BF, Hellman K, Vaziri R, Andersson S and Hellstrom $A C$ : Cervical cancer in the screening era: Who fell victim in spite of successful screening programs? J Gynecol Oncol 22(2): 76-82, 2011
22 Darlin L, Borgfeldt C, Widen E and Kannisto P: Elderly women above screening age diagnosed with cervical cancer have a worse prognosis. Anticancer Res 34(9): 5147-5151, 2014.

23 Gonzalez P, Hildesheim A, Rodriguez AC, Schiffman M, Porras C, Wacholder S, Pineres AG, Pinto LA, Burk RD and Herrero R: Behavioral/lifestyle and immunologic factors associated with hpv infection among women older than 45 years. Cancer Epidemiol Biomarkers Prev 19(12): 3044-3054, 2010.

24 Smith EM, Ritchie JM, Levy BT, Zhang W, Wang D, Haugen TH and Turek LP: Prevalence and persistence of human papillomavirus in postmenopausal age women. Cancer Detect Prev 27(6): 472-480, 2003.

25 Guardado-Estrada M, Juarez-Torres E, Roman-Bassaure E, Medina-Martinez I, Alfaro A, Benuto RE, Dean M, VillegasSepulveda $\mathrm{N}$ and Berumen $\mathrm{J}$ : The distribution of high-risk human papillomaviruses is different in young and old patients with cervical cancer. PLoS One 9(10): e109406, 2014

26 Herrero R, Hildesheim A, Bratti C, Sherman ME, Hutchinson M, Morales J, Balmaceda I, Greenberg MD, Alfaro M, Burk RD, Wacholder S, Plummer M and Schiffman M: Population-based study of human papillomavirus infection and cervical neoplasia in rural Costa Rica. J Natl Cancer Inst 92(6): 464-474, 2000.

27 Rodriguez AC, Schiffman M, Herrero R, Hildesheim A, Bratti C, Sherman ME, Solomon D, Guillen D, Alfaro M, Morales J, Hutchinson M, Katki H, Cheung L, Wacholder S and Burk RD: Longitudinal study of human papillomavirus persistence and cervical intraepithelial neoplasia grade 2/3: Critical role of duration of infection. J Natl Cancer Inst 102(5): 315-324, 2010.

28 Cattani P, Siddu A, D’Onghia S, Marchetti S, Santangelo R, Vellone VG, Zannoni GF and Fadda G: RNA (E6 and E7) assays versus DNA (E6 and E7) assays for risk evaluation for women infected with human papillomavirus. J Clin Microbiol 47(7): 2136-2141, 2009.

29 Cattani P, Zannoni GF, Ricci C, D’Onghia S, Trivellizzi IN, Di Franco A, Vellone VG, Durante M, Fadda G, Scambia G, Capelli $G$ and De Vincenzo R: Clinical performance of human papillomavirus e6 and e7 mrna testing for high-grade lesions of the cervix. J Clin Microbiol 47(12): 3895-3901, 2009.

30 Asciutto KC, Ernstson A, Forslund O and Borgfeldt C: Selfsampling with hpv mrna analyses from vagina and urine compared with cervical samples. J Clin Virol 101: 69-73, 2018.

31 Wang J, Andrae B, Sundstrom K, Ploner A, Strom P, Elfstrom KM, Dillner J and Sparen P: Effectiveness of cervical screening after age 60 years according to screening history: Nationwide cohort study in sweden. PLoS Med 14(10): e1002414, 2017.

32 Arbyn M, Roelens J, Cuschieri K, Cuzick J, Szarewski A, Ratnam S, Reuschenbach M, Belinson S, Belinson JL and Monsonego J: The aptima HPV assay versus the hybrid capture 2 test in triage of women with ASC-US or LSIL cervical cytology: A meta-analysis of the diagnostic accuracy. Int $\mathbf{J}$ Cancer 132(1): 101-108, 2013.

33 Johansson H, Bjelkenkrantz K, Darlin L, Dilllner J and Forslund $\mathrm{O}$ : Presence of high-risk hpv mrna in relation to future highgrade lesions among high-risk HPV DNA positive women with minor cytological abnormalities. PLoS One 10(4): e0124460, 2015.

34 Eltoum IA, Chhieng DC, Crowe DR, Roberson J, Jin G and Broker TR: Significance and possible causes of false-negative results of reflex human papillomavirus infection testing. Cancer 111(3): 154-159, 2007. 
35 Wright TC Jr., Massad LS, Dunton CJ, Spitzer M, Wilkinson EJ, Solomon D, American Society for C and Cervical Pathologysponsored Consensus C: 2006 Consensus guidelines for the management of women with cervical intraepithelial neoplasia or adenocarcinoma in situ. J Low Genit Tract Dis 11(4): 223-239, 2007.

36 Eltoum IA, Chhieng DC, Roberson J, McMillon D and Partridge EE: Reflex human papilloma virus infection testing detects the same proportion of cervical intraepithelial neoplasia grade 2-3 in young versus elderly women. Cancer 105(4): 194-198, 2005

37 Iftner T, Becker S, Neis KJ, Castanon A, Iftner A, Holz B, Staebler A, Henes M, Rall K, Haedicke J, von Weyhern CH, Clad A, Brucker S and Sasieni P: Head-to-head comparison of the RNA-based aptima human papillomavirus (HPV) assay and the DNA-based hybrid capture $2 \mathrm{hpv}$ test in a routine screening population of women aged 30 to 60 years in germany. J Clin Microbiol 53(8): 2509-2516, 2015.
38 Haedicke $\mathrm{J}$ and Iftner T: A review of the clinical performance of the aptima hpv assay. J Clin Virol 76(Suppl 1): S40-48, 2016.

39 Kitchener HC, Almonte M, Thomson C, Wheeler P, Sargent A, Stoykova B, Gilham C, Baysson H, Roberts C, Dowie R, Desai M, Mather J, Bailey A, Turner A, Moss S and Peto J: HPV testing in combination with liquid-based cytology in primary cervical screening (ARTISTIC): A randomised controlled trial. Lancet Oncol 10(7): 672-682, 2009.

Received April 16, 2018

Revised May 17, 2018

Accepted May 21, 2018 